\title{
ASSESSING THE KNOWLEDGE AND PRACTICE OF HEALTH WORKER FEMALE ON DIFFERENT FAMILY PLANNING METHODS IN ORISSA
}

\author{
Narahari Agasti1 , Gurukrushna Mohapatra², Tapas Ranjan Behera ${ }^{3}$, Smaraki Mohanty ${ }^{4}$ \\ ${ }^{1}$ Associate Professor, Department of Obstetrics and Gynaecology, KIMS, Bhubaneswar. \\ ${ }^{2}$ Assistant Professor, Department of Community Medicine, KIMS, Bhubaneswar. \\ ${ }^{3}$ Assistant Professor, Department of Community Medicine, SCBMC, Cuttack. \\ ${ }^{4}$ Postgraduate Student, Department of Community Medicine, SCBMC, Cuttack.
}

ABSTRACT

\section{BACKGROUND}

Family planning is one of the important measures to contain overgrowing population and it provides a positive reproductive life. The adoption of any contraceptive method requires a good knowledge of the use of family planning methods and their benefits/side effects depends on the effectiveness of the counselling and sensitisation of the eligible couples by health care providers at the community level.

\section{MATERIALS AND METHODS}

It was a community-based cross-sectional study carried out in Odisha using multistage sampling method in both tribal \& rural subcentres during June to October 2012.

\section{RESULTS}

Out of 36 Health Workers (Female) interviewed, 15 were working in tribal health centres \& 21 were in rural sub-centres. Majority (89\%) had worked less than 15 years. All were aware about Condom, Oral Contraceptive Pill (OCP) \& Intrauterine Devices (IUD). The different reasons for the non-acceptance of different contraception measures as perceived by HW (F) are headache (41\%) \& weight gain (28\%) for OCP and bleeding (58\%) for IUD. Majority of HW (F) had an opinion of interpersonal communication (IPC) as the best method for convincing eligible couple for any family planning methods to adopt. The different signs \& symptoms to be screened before IUD insertion as perceived by HW (F) are white discharge (92\%), STD (80\%) \& irregular bleeding (33\%). However, only 36\% and 33\% reported bleeding \& infection respectively as consequences of keeping IUD for long time.

\section{CONCLUSION}

The study showed, in spite of having good knowledge among health worker females, utilisation of contraceptives by eligible couple in their respective areas were less because of lack of motivational skill among them and some religious myth \& cultural barrier.

\section{KEYWORDS}

Family Planning Methods, Contraception, OCP, IUCD, Health Worker Female.

HOW TO CITE THIS ARTICLE: Agasti N, Mohapatra G, Behera TR, et al. Assessing the knowledge and practice of health worker female on different family planning methods in Orissa. J. Evolution Med. Dent. Sci. 2017;6(55):4154-4156, DOI: 10.14260/Jemds/2017/900

\begin{abstract}
BACKGROUND
Human fertility is determined by many factors such as customs, morals and habits of social groups with regard to marital obligation of life. Acceptance of family planning methods varies within and between societies and there are many factors which are responsible for such variation at community, family and individual level. ${ }^{1}$ The adoption of any contraceptive method requires a good knowledge of the use of family planning methods and their benefits/side effects depends on the effectiveness of the counselling and sensitisation of the risk population. ${ }^{2}$
\end{abstract}

Financial or Other, Competing Interest: None.

Submission 02-06-2017, Peer Review 28-06-2017,

Acceptance 03-07-2017, Published 10-07-2017.

Corresponding Author:

Tapas Ranjan Behera,

Assistant Professor,

Department of Community Medicine,

SCB Medical College,

Cuttack-753004, Odisha.

E-mail: tapas4behera@gmail.com

DOI: $10.14260 /$ jemds $/ 2017 / 900$
Current scenario, sexuality education and awareness are paramount. Sexuality education comprises of physiological, psychological and social issues related to sex, a lack of which may lead to inappropriate attitudes and practices. ${ }^{3}$ Family planning refers as practices that help individuals or couples to attain certain objectives like to avoid unwanted births, to bring about wanted births, to regulate the intervals between pregnancies, to control the time at which births occur in relation to the ages of the parent and to determine the number of children in the family. ${ }^{4}$ Meeting targets of the Sustainable Development Goals in maternal and neonatal health requires a good and consistent use of family planning services. $^{5}$ Family planning offers a positive view of reproductive life and enables people to make informed choices about their reproduction and well-being. Family planning is one of the important measures to contain overgrowing population. ${ }^{6}$ With this background, this study was planned with an objective to assess the knowledge and practice of health worker female on different family planning methods in Orissa. 


\section{MATERIAL AND METHODS}

\section{Study Design \& Study Setting}

It was a field-based cross-sectional study carried out in tribal and rural subcentres of Odisha from June 2012 to October 2012. The study population included health worker females of respective subcentres.

\section{Sample Size and Sampling Technique}

Sample size calculated for this present study was population proportion with specified relative precision. For this purpose, prevalence of knowledge of health worker female about contraceptive practice was calculated as $90 \%$ by a pilot study conducted in subcentres Rangeilunda Block of Ganjam District. Assuming $90 \%$ prevalence rate at $10 \%$ precision level and 95\% confidence interval the sample size was calculated as 35. Multistage sampling method was used to select the study population. The state Orissa has 30 districts out of which 15 districts were selected randomly for the study purpose. The selections of districts were on the basis of rural and tribal in the ratio 2:1 (10 rural districts \& 5 tribal districts). A total 36 subcentres were selected for this purpose, of which 21 were rural and 15 were tribal.

\section{Methodology}

The district health administration, DSWO, were intimated about the purpose before the commencement of the study. The health worker females were explained about the details of the study and informed consent taken after assuring about confidentiality and anonymity of the information obtained. From selected subcentres the respective health worker females were interviewed to get relevant data. Data was collected by pre-designed and pre-tested questionnaire regarding demographic information of study subjects and knowledge on different types of contraceptive behaviours, their side effects and their practices adopted by the community. Both descriptive and inferential statistics were applied and final analysis was done by using SPSS version 20.0 and $\mathrm{p}<0.05$ taken as statistically significant. For categorical variables, chi-square test was applied regarding any statistical association.

The study was approved by the Institutional Ethics Committee of MKCG Medical College, Berhampur, Odisha.

\section{RESULTS}

Data was collected from 36 female health workers (HWF) out of which 15 belonged to tribal health centre and 21 belonged to rural subcentres. Majority (89\%) had worked for 16-20 years, $8 \%$ worked less than 15 years and only $3 \%$ worked more than 20 years in this field. Regarding knowledge on different methods on birth control it was found that almost all i.e. $100 \%$ knew about condom, OCP, IUD whereas $94 \%$ knew about vasectomy and tubectomy. None of the HW Female working in both rural and tribal areas were aware of MTP as a method of birth control. (Table-I). About perception regarding non-acceptance of different contraceptive measures by the eligible couples, it was found that $41 \%$ of HW F think headache and $28 \%$ think weight gain due to OCP as reasons for non-acceptance. Similarly, 58\% thought bleeding per vagina due to IUD as a reason for nonacceptance; whereas $47.22 \%$ thought of loss of health \& weakness due to vasectomy \& $44.44 \%$ thought failure due to tubectomy for non-acceptance by eligible couple. Dissatisfaction due to condom mentioned by $39 \%$ of $\mathrm{HW}$ F as reason for non-acceptance. (Table -II). Majority (66\%) believed personal communication is the best method for pursuance of IUD than mass media. The different signs and symptoms to be screened before IUD insertion as mentioned by HW F are: white discharge (92\%), irregular bleeding (33\%), STD in antenatal women (80\%) and family planning clients (77\%). (Table -III). Only 61\% had perception to use a new pair gloves for IUD insertion. Almost all knew about washing hands before and after examination and use of sterilised equipment. About $75 \%$ were aware about wearing gloves for pelvic examination. Reason for not using a new pair of gloves for each client is "inadequate supply". Gloves are sterilised by boiling method and used for multiple times, this was mentioned by $75 \%$ of health workers. Regarding knowledge of health worker females on consequences of IUD if kept for longer period, $36 \%$ mentioned about bleeding and $33 \%$ about infection. (Table IV).

\begin{tabular}{|c|c|c|c|}
\hline Methods & Rural & Tribal & Total \\
\hline Condom & $21(58 \%)$ & $15(42 \%)$ & $36(100 \%)$ \\
\hline OCP & $21(58 \%)$ & $15(42 \%)$ & $36(100 \%)$ \\
\hline IUD & $21(58 \%)$ & $15(42 \%)$ & $36(100 \%)$ \\
\hline Vasectomy & $21(58 \%)$ & $13(36 \%)$ & $34(94 \%)$ \\
\hline Tubectomy & $21(58 \%)$ & $13(36 \%)$ & $34(94 \%)$ \\
\hline Diaphragm/Jelly & $2(5 \%)$ & $2(5 \%)$ & $4(10 \%)$ \\
\hline Withdrawal method & $2(5 \%)$ & $1(3 \%)$ & $3(8 \%)$ \\
\hline Emergency pill & $5(14 \%)$ & $3(8 \%)$ & $8(22 \%)$ \\
\hline \multicolumn{4}{|c|}{ Table I. Knowledge of HW (F) on } \\
Different Methods of Birth Control \\
\hline \multicolumn{4}{|l}{} \\
\hline
\end{tabular}

\begin{tabular}{|c|c|}
\hline Methods & Reasons for Non Acceptance \\
\hline OCP & Headache (41\%), weight gain (27\%) \\
\hline IUD & Bleeding PV (58\%), backache (33\%) \\
\hline Condom & Failure (44\%), dissatisfaction (39\%) \\
\hline Vasectomy & Weakness/loss of health (47\%) \\
\hline Tubectomy & Failure (19\%) \\
\hline \multicolumn{2}{|c|}{ Table II. Perception of HW (F) on Reasons for Non- } \\
acceptance of Different Contraceptive \\
Measures by the Eligible Couples
\end{tabular}

\begin{tabular}{|c|c|c|c|}
\hline Sign and Symptoms & Rural & Tribal & Total \\
\hline White discharge & $21(58 \%)$ & $12(33 \%)$ & $33(91 \%)$ \\
\hline Ulcer & $2(5 \%)$ & 0 & $2(5 \%)$ \\
\hline Infection & $6(17 \%)$ & $2(5 \%)$ & $8(22 \%)$ \\
\hline Irregular bleeding & $8(22 \%)$ & $4(11 \%)$ & $12(33 \%)$ \\
\hline Burning on urination & $5(14 \%)$ & $3(8 \%)$ & $8(22 \%)$ \\
\hline Severe itching & $15(41 \%)$ & $12(33 \%)$ & $27(75 \%)$ \\
\hline Other signs of STD & $4(11 \%)$ & $5(14 \%)$ & $9(25 \%)$ \\
\hline \multicolumn{3}{|c|}{ Table III. Perception of HW (F) to Look any } \\
Sign and Symptoms before IUD Insertion \\
\hline
\end{tabular}




\begin{tabular}{|c|c|c|c|}
\hline Consequences & Rural & Tribal & Total \\
\hline Difficulty in removing & $3(8 \%)$ & 0 & $3(8 \%)$ \\
\hline Displacement of IUD & $4(11 \%)$ & $2(5 \%)$ & $6(16 \%)$ \\
\hline Bleeding & $12(33 \%)$ & $1(3 \%)$ & $13(36 \%)$ \\
\hline Infection & $4(11 \%)$ & $8(22 \%)$ & $12(33 \%)$ \\
\hline White discharge & $4(11 \%)$ & $1(3 \%)$ & $5(14 \%)$ \\
\hline Backache & $5(14 \%)$ & $3(8 \%)$ & $8(22 \%)$ \\
\hline Rupture of uterus & $1(3 \%)$ & $3(8 \%)$ & $4(11 \%)$ \\
\hline Cancer & $3(8 \%)$ & $2(5 \%)$ & $5(14 \%)$ \\
\hline Can conceive & $1(3 \%)$ & $2(5 \%)$ & $3(8 \%)$ \\
\hline Do not know & $2(5 \%)$ & $2(5 \%)$ & $4(11 \%)$ \\
\hline
\end{tabular}

motivational skill of the HW (F) through re-orientation training with updates at regular intervals to overcome these barriers and increase the usage of modern contraceptive methods.

\section{Limitation of the Study}

Health Worker Female from urban areas were not studied.

Strength of the study is that Health Worker Female working in both rural and tribal areas were included in the study.

Weakness of the study- A small sample size.

\section{REFERENCES}

[1] Hayat H, Khan PS, Imtiyaz B, et al. Knowledge, attitude and practice of contraception in rural Kashmir. J Obstet Gynaecol India 2013;63(6):410-4.

Among common contraceptive practices, vasectomy and tubectomy was less known to health worker female working in tribal areas. This may be due to low awareness drive or lack of interest or educational training. The most reliable and most commonly used contraceptive is condom with less failure rate. But this study reveals that there is a high failure rate and dissatisfaction which indicate that they require a strong, motivational training on contraception. Most of the health workers believed that white discharge, itching associated with IUD insertion are probable side effects which require a qualitative training and effective demonstration to overcome the deficit on knowledge on IUD insertion. According to a study conducted by K. Nivedita, it was found that only $43.24 \%$ were sure about indication for emergency contraception where in our study $22 \%$ were aware about emergency contraception. ${ }^{7}$ A study conducted by Keerti et al ${ }^{8}$ regarding knowledge on emergency contraception among nursing students it was found that $55.71 \%$ students gave the correct response to ideal clients for emergency contraception. A study by Chakraborty et $\mathrm{al}^{9}$ found that between $20 \%$ and $35 \%$ of providers consider the common side effects of painful menstruation, cramping, and excessive bleeding unacceptable while in this study bleeding and infection are the most common side effects associated with IUD. In a study by Eve Espel et al, overall $69-78 \%$ of providers had good factual knowledge about the IUD and felt adequately prepared to insert a device or counsel women about it whereas in this study $92 \%$ were aware about side effects and when to insert an IUD. 10

\section{CONCLUSION}

Women must be made aware about their right, i.e. protecting their own health. Good counselling practices by HW (F) through interpersonal communication (IPC) with giving a cafeteria choice to the eligible couples are the need of the time. In spite of having good knowledge about family planning methods \& positive attitude among the HW (F), there are some factors like desire for motivating the eligible couple and fear of common side effects lead to non-use of contraceptives. So, it is important to improve the

[2] Ajong AB, Njotang PN, Kenfack B, et al. Knowledge of women in family planning and future desire to use contraception: a cross sectional survey in Urban Cameroon. BMC Res Notes Bio Med Central 2016;9:347. http://dx.doi.org/10.1186/s13104-0162155-7

[3] Mutha AS, Mutha SA, Baghel PJ, et al. A Knowledge, attitudes and practices survey regarding sex, contraception and sexually transmitted diseases among Commerce college students in Mumbai. J Clin Diagn Res 2014;8(8):HC14-8.

[4] Park K. Park's text book of preventive and social medicine. 23rd edn. M/s Banarsi Bhanot Publisher 2015: pgs. 936.

[5] Das D, Mandal AK, Halder S, et al. Pattern of injuries caused by animal and management among patients attending at out-patient department of a rural medical college, West Bengal, India. IOSR J Dent Med Sci 2015;14(4):55-9. www.iosrjournals.org

[6] Choudhary D, Pal R, Goel N. Awareness and practice patterns of family planning methods among antenatal women in Indian community: are we hitting the bull's eye? Biomed J 2015;38(4):356-8.

[7] Nivedita K, Shanthini FN. Knowledge, attitude and practice of emergency contraception on nursing personnel. J Clin Diagn Res 2014;8(9):OC20-22. http://www.ncbi.nlm.nih.gov/pubmed/25386489.

[8] Keerti SJ, Pravin NY. A study of knowledge and attitude of nursing students towards emergency contraception. Int J Med Res Health Sci 2013;2(3):5014.

[9] Chakraborty NM, Murphy C , Paudel M, et al. Knowledge and perceptions of the intrauterine device among family planning providers in Nepal: a crosssectional analysis by cadre and sector. BMC Health Services Research 2015;15:39.

[10] Espey E, Ogburn T, Espey D, et al. IUD-Related knowledge, attitudes and practices among Navajo area Indian health service providers. Perspective on Sexual and Reproductive Health 2003;35(4):169-73. 